\title{
WRITING THE ARMENIAN \\ GENOCIDE IN EVE MAKIS'S \\ THE SPICE BOX LETTERS: \\ TRAUMA, DIASPORA, COMMUNITY
}

Brno Studies in English

Volume 46, No. 2, 2020

ISSN 0524-6881 | e-ISSN 1805-0867

https://doi.org/10.5817/BSE2020-2-13

\section{JOPI NYMAN}

\begin{abstract}
This essay examines the role and representation of the trauma of the Armenian genocide in the recent novel The Spice Box Letters (2015) by the British Cypriot writer Eve Makis. Set in 1985 and based on stories told by the diasporic Armenian community, the novel is concerned with the history of the Armenian genocide of 1915 and explores its traumatic effects on different generations in the form of witnessing, the refugee experience, displacement, and diaspora. The essay applies the conceptualization of trauma representation as presented in Michael Rothberg's study (2000) and in Marianne Hirsch's (2008) notion of postmemory, which understand trauma and post-trauma as multi-layered, generational responses to the original event. By including both narratives by witnesses of the genocide and other family members living in diaspora, the novel explores the intergenerational character of the traumatic experience and the resultant displacement, and addresses ways of overcoming the traumatizing past. It brings together the dispersed family members and unites them with the larger diasporic community by using the idea of constellation both literally and figuratively in the narrative to imagine new affiliations with tradition and community.
\end{abstract}

Key words

Eve Makis; Cypriot writing in English; Armenia; genocide; trauma; diaspora

\section{Introduction}

This essay examines the role and representation of the trauma of the Armenian genocide in the recent novel The Spice Box Letters (2015) by the British Cypriot writer Eve Makis. A novel not addressed by previous critics, it is set in 1985 and based on stories told by the diasporic Armenian community (see The Armenian Mirror-Spectator 2016). Concerned with the history of the Armenian genocide of 1915, the novel explores its traumatic effects on different generations in the form of witnessing, the refugee experience, displacement, and diaspora. ${ }^{1}$ Through the narrative of its protagonist, British-born Katerina, and her search for her lost family history and ethnic identity in present-day Cyprus, The Spice Box Letters shows an attempt to engage with the silenced story of her late grandmother and her family, available only in letters and a diary found hidden away in an old spice box. Written in Armenian, these are inaccessible to Katerina and her mother Gaby, who require external help. As the novel reveals during Katerina's journey 
to Cyprus, where she meets Ara, a young Armenian man, who interprets the journal for her, the traumatizing effects of the genocide are central to the surviving family members living in diaspora in the United States, Britain, and Cyprus, but with no contact with each other. The trauma, the novel suggests, is both individual and also cultural and diasporic.

The theoretical framework of the essay is based on the conceptualization of trauma representation as presented in works such as Michael Rothberg's Traumatic Realism (2000) and in Marianne Hirsch's (2008) notion of postmemory, which take into account both trauma and post-trauma as multi-layered, generational responses to the original event and their different representation. As I will show, Makis's novel approaches these through the grandmother's journal and the granddaughter's story and her search for identity. By including both narratives by witnesses of the genocide as well as those by other family members living in diaspora, Makis's novel addresses the intergenerational character of the traumatic experience and the resultant displacement, representing it as in a register of pain, silence, and loss. What I will suggest is that by uncovering silenced histories of displacement, The Spice Box Letters is engaged in recovering and rewriting the cultural memory of the genocide, a process in which other literatures such as recent Kurdish literature in Turkey have also been involved, albeit from a different position (see Galip 2016; Çelik and Öpengin 2016). Following a discussion of key concepts such as traumatic realism and postmemory and their relation to the novel's thematic of diaspora, I will read Makis's novel within this frame to show how it examines the traumatic memory of the genocide in the context of displacement and the identity reconstruction of the Armenian diaspora. In addressing the legacies of the traumatizing moments, The Spice Box Letters revises established understandings concerning the reconstruction of identities in the context of the Eastern Mediterranean and its histories of migration.

\section{Traumatic realism in times of forced migration and diaspora}

Through exploration of migration and trauma in the context of the Eastern Mediterranean, Makis's novel shows how extensively identities in the region are mobile, and the extent to which cultures and phenomena are in constant touch with others through contact zones and migration. James Clifford has shown how cross-cultural movement problematizes conventional dichotomies such as "native" and "traveller" and "dwelling/traveling" (1992: 24), suggesting that different modes of mobility - of people, culture, and texts - challenge nationalisms and fixed identities. Such mobilities, however, are not always voluntary, but may have been forced upon displaced and diasporic subjects, who carve out identities through their journeys, inhabiting spaces of in-betweenness and diaspora, locating them in more than one fixed setting. This is also the case in The Spice Box Letters and its Armenian characters that are dispersed globally, While the novel's constructions of mobility emerge through transnational movement across diverse borders where identities transform, such changes are generated by the 
traumatizing effects of the genocide, forced migration, and diaspora, rather than indicating conventionally more positive processes such as hybridity or cultural mixing. In my analysis, I will address Makis's representation of the legacies of displacement, forced migration, and diaspora identities with the help of Michael Rothberg's (2000) concept of traumatic realism, and supplement that with Vijay Mishra's (2007) work on diaspora trauma in order to locate the specificities of Makis's representation of intergenerational trauma.

Rothberg's term, constructed in the context of Holocaust studies, is a means of narrating what he calls "extreme moments" (2000: 11). An attempt to rethink the concept of realism and its overemphasis in Holocaust studies, as well as a critique of postmodernist tendencies to underestimate the historical and the experiential, traumatic realism provides an approach to the cultural processing of genocide that, in Rothberg's view, "mediates between the realist and antirealist positions in Holocaust studies and marks the necessity of considering how the ordinary and extraordinary aspects of genocide intersect and coexist" (2000: 9). The term "realism" - which is usually understood as a period term - is redefined in Rothberg's work. For him, realism, modernism, and postmodernism emerge as what he calls "persistent responses to history" that generate ways to implement "the representation and interpretation of history" (2000: 9), not as literary periods or stylistic movements. As Rothberg writes:

In the representation of a historical event, in other words, a text's 'realist' component seeks strategies to document the world; its 'modernist side' questions its ability to document history transparently; and its 'postmodern' moment responds to the economic and political conditions of its emergence and public circulation. (2000: 9)

Rothberg's version of realism, then, is not a mere or naive representation of what has happened, since history is accessible only indirectly, as he suggests (2000: 9), and is thus suitable for the analysis of Makis's contemporary text. Unlike in some other narratives addressing the trauma of the Armenian genocide without openly representing as discussed by Michael Pifer (2016), in Makis's novel it is witnessed and its intergenerational legacy revealed.

Rothberg's work is part of a critical debate concerning the Holocaust and its representation where the boundary between realism and antirealism has played a crucial role. The proponents of the former view promote what Rothberg calls realist views that explain the Holocaust in the contexts of modernity and science (e.g. Hannah Arendt, Daniel Goldberg), whereas the antirealist position is evident, for example, in Elie Wiesel's insistence that the Holocaust can be understood only by those who have experienced it (2000: 4-5). In the context of the Holocaust, its representation has often been found problematic following Adorno's claim of the impossibility of writing poetry after Auschwitz. It has been suggested, for instance, that fiction may falsify real memories of the Holocaust and misrepresent human suffering, thus accepting only what they see as authentic accounts (for an overview, see Franklin 2011: 5; cf. also Scheiber 2009: 7-9). In a similar way, many museum curators and researchers have faced over the years 
what Eaglestone and Langford allude to as "tension between scholarship and respect for the dead" (2008: 2).

In contrast to such views, and especially since the historical distance from the events has increased, fiction has become a significant way to address the cultural processing of the Holocaust, including understanding its postmemory, this is, its significance to those who have experienced the trauma in their lives through family histories (see Hirsch 2008), or its role as a didactic means to educate different audiences on history (see Dean-Ruzicka 2017: 13-16). Rothberg's conceptualization, then, rather than privileging the documentary or other such modes of realism - or possibly also denying their importance - is a useful tool capable of addressing the development of the artistic processing of extreme moments, such as may be found in Makis's novel. This is necessary especially in the current cultural situation where first-generation memoirs by survivors have been supplemented with different forms of Holocaust narratives conveyed through, e.g., family narratives, films, and other forms of popular culture, indicating the intergenerational transmission of extreme moments.

As this shows, the modifying adjective traumatic in Rothberg's concept is particularly important: it implies that traumatic realism can be expressed through different modes of representation, including both realism and postmodernism. Rothberg's key example is Art Spiegelman's famous Holocaust-related graphic novel Maus (1984), which uses the signifier mouse in three distinct ways that are brought together in the following to illustrate their relationship with each other:

$$
\begin{aligned}
& \text { mouse - documentation - realism - survivor } \\
& \text { Maus - self-reflective aesthetic form - modernism - bystander } \\
& \text { Mickey Mouse - public circulation - postmodernism - latecomer } \\
& \text { (based on Rothberg 2000: } 10 \text { and 13) }
\end{aligned}
$$

This tripartite model, Rothberg suggests, is indicative of a certain "tension" between its elements and comprises what he, on the basis of Walter Benjamin's work, terms a "constellation", that is, "a sort of montage in which diverse elements are brought together through the act of writing" and one that underlines the fact that any understanding of history is an interpretation (2000: 10). In the view of Rothberg, these constellations are particularly useful ways of representing and understanding extreme moments that are not limited to a single place or time, such as the Holocaust or the Armenian genocide.

As is also evident in Makis's novel remapping forced migration induced by the traumatizing events, their effects are wide-ranging, often extending beyond the borders of the nation-state or to different continents through displacement, exile, and forced migration - here to Cyprus, Britain, and the United States. In terms of temporality, such events are not limited to a particular historical moment, but their impact is felt by several generations, thus revealing their highly traumatizing character. According to Rothberg, this does not underestimate the experience of the survivors of the original event; rather, it is important to pay attention to "the psychic and social aftermath of genocide, as well as the problem of the transmission of knowledge" (2000: 12). Events such as genocide are transmitted from one 
generation to another and are a part of the constitution of their identity. As suggested in Marianne Hirsch's concept of postmemory, this is, "a consequence of traumatic recall [...] at a generational remove" (2008: 106), which, as I will show, plays a major role in the novel's characters' ways of addressing the past.

The concept of traumatic realism can be brought into dialogue with diaspora studies, since the key experiences in diaspora can often be interpreted through the concept of trauma. Many diasporas are generated through forms of displacement, such as slavery, forced labour, and forced migration, and their narratives often articulate such legacies. In this context, Vijay Mishra's work on diaspora as trauma is relevant, since in his view the diaspora experience can be seen as a form of Freudian melancholia, a pathological mourning that the members of the diaspora always carry with them: "the diasporic imaginary is a condition [...] of an impossible mourning that transforms mourning into melancholia" (Mishra 2007: 9). For Mishra, the concept of the imaginary refers to the self-image and the ambiguous relationship between the dominant and the diasporic where diasporas are always built upon trauma haunting its members: "If, for the dominant community, diasporas signify their own lapsed enjoyment of the Nation Thing, for diasporas to face up to their own ghosts, their own traumas, their own memories is the necessary ethical condition" (2007: 16). Diaspora trauma, Mishra suggests, needs to be addressed so that the mourning could come to an end. From a different perspective, Rothberg, in a discussion juxtaposing philosopher Maurice Blanchot's pre-war right-wing, anti-Jewish writing with his postwar reflections on the ethical problems of his earlier work, shows Blanchot's implication in trauma and also claims that a similar encounter with one's past is required should one wish to come to terms with the past: "his [Blanchot's] innovation is the implicit suggestion that such repetition and reordering can be crucial to a working through of a traumatic loss" and in order to form a "proper ethical stance to take in relation to the past" (2000: 24). Makis's novel is an example of such repetition and reprocessing, as it works through the history of forced migration from Armenia to Cyprus but also addresses the traumas of its Armenian characters living in diaspora.

In my reading of Makis's novel I follow the framework presented above. I will first analyze the novel's representations of extreme moments and trauma, then continue with a discussion of its use of the notion of constellation, and finally discuss the ways in which the novel's Armenian diaspora faces its own traumatizing past in order to reconstruct identity and community. In so doing, I present a reading of the novel that, by using the concept of traumatic realism, reveals the effects of intergenerational trauma on the family at the centre of the novel, whose lives are overshadowed by a past that is partially unknown to them.

\section{Witnessing and experiencing trauma in The Spice Box Letters}

While addressing a historical and cultural trauma, the genocide of Armenians and the formation of their diaspora, The Spice Box Letters is also a postmodernist historical novel that provides a narrative version of contested history by weaving 
fact with fictionality. Makis's novel works at several levels; it contains a detailed account of the atrocities of the genocide by those who have witnessed them, and combines that with a plot centring upon silenced family history that the descendants of the first generation aim to solve. In so doing, Katerina and her mother reconstruct their identity as members of the Armenian diaspora generated by and carrying the trauma of the genocide. In so doing, the novelist rewrites a history silenced by official narratives, and argues for the need to recognize its effects in order to be able to find recuperation.

The thematics of trauma form the core of the novel from its first chapter. It shows Mariam, aged 7 at the time, and her father Baba, the town doctor, arriving at the city's market square, where they witness an attack on the Armenian baker Kalfayan by a number of police officers, in which their Turkish commandant is hitting the baker with his baton so that the latter's "head dashe[s] against the cobbles" (26). When the father saves Kalfayan, he is taken into custody and soon executed. In 1915, as the novel reveals, the atmosphere of Caesarea in Eastern Turkey is ripe for conflict, and the young girl's childhood nightmares soon turn into geopolitical fears. The Armenian minority, with its own culture and way of life, is seriously threatened by the majority:

Did other girls lie awake at night gripped by fear and dread? Did sleep bring vivid nightmares that haunted them throughout the day? Was life, on the other side, blighted by war? [....]

Once, I had feared mythical creatures, monsters and spooks. Now I had to contemplate threats that were real: men on horseback, wielding guns and knives, sinking metal into flesh and riding away with human loot.

The Turks had joined forces with the Germans and declared war against France, Great Britain, and Russia. [....] The government blamed the Armenians for its defeats, accusing us of siding with the enemy. Armenian communities had come under attack from vigilantes who rode into towns and villages at midnight, torching homes, looting, abducting women and adolescent girls. (11)

In the following chapters addressing the genocide, the novel explicates how the town's Armenians are aware of the eventuality of the conflict but unable to change the course of events. This awareness is addressed in the words of Carabetian, a lawyer portrayed as a spokesman for the Armenians, who in the novel are considered second-class citizens in comparison to Muslims: "The law can't protect us [...] Only a gun can do that. Friends, I urge you all to keep a loaded rifle for any eventuality" (41). Others find Carabetian a mere "scaremonger" and cynic, as they believe in the help of Europeans should "real trouble" emerge (42). The scene, however, reveals that Carabetian's view is correct, as it culminates in the arrival of Turkish police at the celebratory wedding, transporting away the groom as well as the lawyer and Mariam's father. This arrest leads to the torture and death of the Armenians: "He [Carabetian] was hanged upside-down, the bottoms of his feet sliced off, his raw flesh ladled with salt. Failing to secure a confession, his torturers pulled out his toenails with pliers and left him suspended, blood pooling in his brain" (45). Baba, 
for his part, beaten unrecognizable by his capturers, is also hanged in public, and his shocked family watches the execution amidst the audience (46).

While the deaths of the father and other family friends are highly traumatizing experiences, they are just the beginning of the ordeals of Mariam and her family and the long marches associated with the genocide. The novel shows how the Armenians are forced to sell their possessions, leave the town, and set out on a long journey towards exile and protection with only their most precious valuables. In preparation for the journey, which takes some them to the United States and its promise of freedom and liberty, as some of them imagine, but others to their death, Mama cuts Mariam's hair and dresses her as a boy to ensure her safety - as later events show, beautiful girls such as their friend Esther are captured and never heard of again. The hostility of the Turkish population is evident when the Armenians leave the town as a large group. By comparing them to insects, Mariam's words underline the Armenians' sense of dehumanization:

We joined the masses streaming out of the city, like ants hosed out of their nests. Some of the women wore smart European jackets and log skirts, others were dressed in crumpled smocks and had scarves tied around their shoulders and heads. I was not alone in donning a guise. Many girls had had their faces daubed with earth and coal to mask their good looks. A line of Turkish soldiers walked alongside us, lashing out with their batons, hitting donkey hide or the head of a laggard. Screams and the pounding of the doors was our soundtrack out of the city. Those who refused or were unable to leave were dragged out of their houses. I stared into empty homes through gaping doors, shattered shutters. (57)

The description of the Armenians as "masses" whose movement is patrolled by force indicates the extent to which their mobility is forced upon them. As unprotected refugees, the Armenians travel through waterless landscapes, with only each other as companions who can be trusted. As they run out of provisions, the children and the elderly are unable to cope. One scene of death and violence is followed by another: they come across dead babies in ditches (58), an armed Kurdish vigilante snatches Esther for his pleasure (59), and the "acrid" stench of decaying corpses surrounds them (63). Mariam describes her own situation in a way that emphasizes her transition from civilization and purity to a world associated with dirt and Otherness: "I had grown used to the filth, the stench of unwashed skin. Lice infested my clothes, the matted tufts of my hair. I scratched constantly, making my scalp bleed and crust. I had stopped asking my mother for food and tried to ignore the hunger pains that twisted my gut and made me gasp" (63). Under these conditions, it is no surprise that the promise made by a group of Turks to take 20 boys - including Mariam and her both brothers - to be fed at a school, is too appealing to their well-meaning mothers. The scheme turns out to be a cunning hoax culminating in mass murder in a remote forest:

The cart came to a stop in a clearing and we were told to climb down. We huddled together, glancing around. There was no schoolhouse, no food or 
clothes to be seen. A songbird trilled for a mate, the singing at odds with the cold fear that wrapped me in a dank shroud. While the driver looked on impassively, the guards moved closer, began circling us, and then, without warning, they lashed out with the bayonets, stabbing and slashing, cutting into flesh while startled swallows rose from the trees, their wings fluttering.

Some boys were taken by surprise and fell silently; others tried to run away. They were pulled back by the hair, their throats slit. (65)

The description of the extreme moment is graphic and almost documentary; the emotions of the victims remain unexplored and the emphasis is on the acts of violence on the body. To use Rothberg's terms, the narrating subject here is a survivor who is traumatized first by the scene they witness and later by the loss and death of their siblings and friends: "The children lay tangled around me, their heads thrown back and their mouths agape or horribly twisted, terror cemented on their faces" (65). Three children, however, survive: Mariam is joined by Levon, "caked in dirt, a subhuman being, eyes spilling with fear" (66); later her brother Gabriel is also saved by a Turkish woman whose family displays kindness, but, fearing for the safety of their family, they cannot raise him as their own.

This break-up of the family is at the core of the trauma that follows the characters throughout their lives. This trauma is generated by displacement and mobility, where the Eastern Mediterranean plays a role by generating the novel's "poetics of location", to use the term in Rothberg's sense, indicating that the text resonates with the historical and geographical context of the genocide. Starting from eastern Turkey, the journey takes some characters to the notorious Deir ez-Zor camps in the Syrian desert, while others reach Lebanon and the Mediterranean, which offers a route to Cyprus, Europe, and the United States, locations for a new life. As Gabriel reflects on his boat trip to Cyprus:

I found myself aboard a sailboat crowded with refugees headed for Cyprus. Armenian families packed the deck, sitting on rugs and cushions, huddled around their few possessions. The First World War had ended and displaced people around the world were rebuilding their lives. Armenians sought out safe havens, joining relations in Europe and America, our plight a footnote in history, dwarfed by the calamity of world war. [...] I was a released prisoner, overwhelmed and unsettled by my strange, newfound freedom. (114)

Following Rothberg's theory, it could be suggested that the boat full of migrants is a site of memory, revealing the need to reconstruct identity, but it also tells of the loss of one's homeland, now inaccessible and full of traumatic memories of the genocide. Such "temporal turning points" (Rothberg 2010: 195) position the re-forming ethnic identity in the novel as one of in-betweenness and diaspora, haunted and traumatized by loss of home and community.

Forced mobility and sense of insecurity characterize the displacement and add to the traumatizing loss of family and safety. While Mariam and Levon are 
adopted by Rose, a British nurse, and taken to England, and Gabriel finds his lost uncle Nareg in Cyprus after the war, in 1919, the siblings remain unaware of each other's survival, regardless of attempts to locate possibly surviving relatives. In the course of time, Mariam and Gabriel choose to deal differently with the trauma afflicting them. Mariam becomes silent and does not speak about her background and experiences to her family. She even refuses to teach Armenian to her daughter Gaby ("learning Armenian wouldn't help me [Gaby] in life" [7]). Following her marriage in Britain, she develops a new identity as the wife of an English doctor, John, who is described as a "quintessential English gent, respected local GP, a fan of corduroy trousers and cardigans with leather elbow patches" (7). Mariam's way to cope with trauma involves rejection and silence, while trauma itself is explored only in her private journal found after her death in the mysterious spice box. Gabriel, however, finds his way to a Lebanese orphanage where Armenian children are given Turkish names and treated harshly, until the Americans take it over at the end of the war and the new management encourages the boys to address their traumatic experiences by painting and drawing. Later, in Cyprus, Gabriel is able to explore with his uncle his painful trauma and the "haunting" events involving death and terror (120), and continues talking about the past to the American anthropologist Jennifer who is interviewing members of the diaspora in the present-time of the narrative.

Unable to forget and come to terms with the past, however, Gabriel has become strongly committed to his Armenianness and promotes ethnic purity to the extent that he refuses to accept that his granddaughter Anahit wishes to marry a Cypriot Greek. Exogamy, in his view, is equated with betrayal and is merely "cultural genocide. The undoing of everything your ancestors suffered for, everything I suffered for" (171). In addressing Gabriel's exclusionist attitude, the novel shows how also characters with no first-hand memory become affected by trauma and carry it in their lives, which is suggested in Marianne Hirsch's (2008) notion of postmemory, a concept suggesting that later generations may experience the trauma of an earlier one. For Hirsch, postmemory is "a structure of inter- and trans-generational transmission of traumatic knowledge and experience. It is a consequence of traumatic recall but (unlike post-traumatic stress disorder) at a generational remove" (2008: 106; emphasis original). The experience of the trauma by the second and third generation is seen in the novel: while Gabi and Katerina lack knowledge of Mariam's past and feel the lack, Anahit is forced to suffer because of her grandfather's unresolved trauma and ethnic absolutism. The trauma is also an example of diaspora trauma in Mishra's postmemory: continuous melancholia seems to affect Gabriel in particular, as he chooses to dwell in the past.

Gabriel's strong views that lead to his rejection of Anahit's fiancée are enhanced by the fact that he is forced to re-experience the trauma of his childhood during the Cyprus crisis of 1963-64. As a part of the armed conflict in December 1963 between the Greek and Turkish communities, his house becomes located in the military zone and is threatened by the battles. While his wife Marta and daughter Tamar are evacuated, Gabriel decides to stay at home. In so doing, however, he is forced to re-enact his trauma of the loss of his family: "I couldn't bear to watch my family leave as I had once watched my mother and Alitz [a young orphan 
travelling with his family] disappear into the unknown" (182) - in terms of Mishra's diaspora trauma, Gabriel is living in a state of continuous mourning that has no end (cf. 2007: 9). Examining his photograph albums and reflecting on the past, he decides that this time, however, he will still have mementos of his family life, even if his house and furniture were to disappear, when he packs up and chooses to leave to join his family:

Without Marta I felt abject loneliness and when my solitude became unbearable, I unhooked the pictures from our walls: my girl growing up, her wedding, cherished snaps of my grandchild, the sole surviving pictures of my father. I packed every last picture in a suitcase along with the negatives. This time, my memories, at the very least, would be saved. I waited for the break in the fighting, moved the furniture aside, stepped into daylight and walked, brandishing a white handkerchief, suitcase in my other hand, as I made my way to the nearby checkpoint at Ledra Palace. (183)

Marianne Hirsch suggests that family photographs related to worlds that have been "annihilated by force" reveal "intimate material and affective connection[s]" as well as "diminish distance, bridge separation, and facilitate identification and affiliation" (2008: 116). This is certainly the case in Makis's novel - both Gabriel and also Gabi and Katerina look at family images to "bridge separation." The latter, in particular, when examining Mariam's possessions following her funeral, look at and talk about their family's snapshots, indicating their strong involvement in postmemory. While they have limited knowledge of Mariam's childhood in particular, they are aware of its impact in their lives and they have a wish to address and deal with the silenced past. In other words, the trauma of the genocide is present every day in the lives of the novel's Armenians, regardless of their generation.

\section{Encountering the trauma: From photographs to constellations}

When read in the context of Rothberg's model of traumatic realism, the novel's references to photography, and to the photograph of the father in particular, are highly important and reveal other relevant issues linked with recuperation from trauma. This would demand the recognition of the past in the present, which Mishra refers to as the diaspora's need to face its ghosts (2007: 16). What is important here is the role of photographs as markers of the past, which I will address first, as well as the role of other traditions maintaining identity in diaspora, to be discussed later in this section.

In the case of photographs, the fact that Gabriel has become a photographer by profession is clearly relevant. As such, he has been actively involved in documenting the pains and pleasures of others through the distancing lens, which at one level indicates his sense of being an outsider but also emphasizes the importance of documentation more generally as a means of linking the individual with the lost histories of family and community. As Gabriel puts it, "I wished I had more pictures of my family, that I had taken photos instead of bread on the day 
we were forced from our home" (160). The photograph of the father - which actually is one half of a picture of his parents, the other half, now in Mariam's possession, depicting the mother - functions to reveal the psychic aftermath of the trauma that he has not worked through, and only when the two parts are put together can recuperation start.

What characterizes traumatic realism as a literary mode, Rothberg suggests, is that details - including references to objects such as photographs - in such narratives can be interpreted "as pointing to the real instead of claiming to be the real" (2000: 104; emphasis original), which makes them indexical in nature. The torn photograph of the father and mother gains particular importance as it is a precise example of what Rothberg defines as "the traumatic index" that "points to a necessary absence" (2000: 114); another similar example is the grandfather's silver watch treasured by Mariam, of which Gabriel has a cheap copy. The photograph shows that, while the father is present, the mother is not - and in the case of the mother the holder of the photograph, his sister Mariam, also remains absent. In the same way, Mariam, whenever she looks at her half of the photograph on her mantelpiece, feels a similar lack that she has coped with by not talking about the past: "She rarely talked about her kin, as if she had taken a vow of silence, an absence of speech that spoke volumes" (6). Thus, the traumatic index works similarly in different contexts.

The resolution of Gabriel's trauma is addressed only in the final chapters of the novel, which reveal how this absence is filled. The novel shows how Katerina and Ara manage to discover that there is a potential relative, a man called Arakelian, living in Nicosia, Cyprus, and they travel there to meet him. When they meet, however, Gabriel, who is bedridden and depressed by a trip to the United States that has only confirmed the death of his mother and her new-born son in Syria in 1918, initially refuses to believe that Katerina is Mariam's granddaughter but thinks that their arrival with the other half of the photograph is a "sick joke" (227). "She had my sister's eyes but still I refuse to believe" (228), he thinks, and only when he sees his father's pocket watch with the engraving of his name does he accept the situation. The resolution of Gabriel's trauma is shown in his psychic and physical response:

My visitor smiles, Mariam's beautiful smile, and I realise that I had not hoped in vain, that the day I had dreamed of all my life has finally materialised.

She lays her head on my chest, soft curls falling across my face, scented with orange blossom. I stroke her hair with clumsy old hands and my heart relaxes for the first time in eons and the tears flow, leaching every ancient misery out of me, great sobs that make my body convulse and take away my breath. I weep for all the beloved people I have lost, but most of all I shed tears of divine happiness for the angel whose cheek lies against my heartbeat. (229)

For our understanding of this process the idea of constellation discussed above is important since it makes it possible to link the past with the present so that the 
ongoing presence of past extreme moments can be grasped - the photograph of the father is a simple version of the constellation. However, The Spice Box Letters develops the notion further, since the narrative itself appears as a constellation, both in terms of its composition and also literally. What this means is that the narrative shows the presence of realist features through its acts of witnessing terror while also utilizing modernist and postmodernist techniques such as multiple narrators, storytelling, and historiographical metafiction, and thus becomes a constellation in the sense proposed by Rothberg.

The narrative structure of the novel is undoubtedly constellation-like. It consists of several accounts, including the frame narrator Katerina's story of her search for identity, which takes her in 1985 from Britain to Cyprus; her grandmother Mariam's journal written in Armenian, which is discovered after her funeral and covers the years 1915-1921; her great-uncle Gabriel's narrative, which tells about his journey from Turkey and Lebanon to Cyprus and focuses on events in his life between 1915 and 1985; and it also reproduces several unsent letters written by Mariam to Gabriel. Representing different aspects of the Armenian diaspora generated by the genocide, the characters, while unaware of each other's existence and traumatized by their alleged loss of family and community, form a globally dispersed entity united by a common history of a homeland and its culture. In order to emphasise that their identity is fully constructed in relation to each other and as a family, the novel resorts to storytelling and uses a folktale told by Gabriel to Mariam upon their escape from eastern Turkey and into apparent safety. The tale aims to explain the origins of the stellar constellation of the Seven Stars and tells of an unlucky couple who are forbidden to marry and eventually die:

"He was a goat herder and she was the daughter of the town's richest man. Her mother, a mean, manipulative woman, sent her away to a distant land to keep her from the boy. Years later, the girl returned to the river where she found the youth, lying just where she had left him, his skin shimmering. When he saw her, he rose into the sky with a flourish of seraphic wings and then, all of a sudden, he fell to earth and died. The girl's heart broke and she died too and the couple were buried together, becoming stars and ascending to heaven. Overcome with grief, the youth's five brothers passed away. One by one they rose into a sky as dark as henna paste where they glimmered like fireflies for all eternity." (61)

In the novel, this story serves to provide a glimpse of the hope the protagonists had felt when they had been forced to leave their hometown upon the murder of their father and other friends. While Mariam interprets the tale as "a sad story" (61), Gabriel insists that its promise of being "reunited in heaven" provides an antidote to their despair and loss of home and father. The importance of the story is developed further in a late scene in which Katerina and her mother, in search of the people mentioned in Mariam's story, visit Levon's restaurant in New York. Called "The Seven Stars," it is appropriate for the reunion of the family as it is in this scene that Levon is informed that he has a daughter and a granddaugh- 
ter and is united with them. The link with the folktale and the family is made clear when Katerina later reflects on the experience of locating her great uncle Gabriel and directs her gaze at the "Mediterranean sky" with its "peppering of stars" and "celestial mystery" (231). As she puts it: "I don't count them. I want to believe there are seven, that Gran, her parents, Rose, Ernest, Tovmas and Esther are gathered together above us, reunited" (232). Signifying an end to the traumas generated by diaspora and genocide, the sense of being together is enacted twice in the above passage where the remaining family members not only gain contact with each other but are also able to refer to those who were once significant in their familial past.

\section{Countering the trauma through ethnic traditions}

This reconstruction of family is embedded in a larger narrative of ethnic tradition and identity that aims to counter the traumas of the past and their effects. In carving out such an identity, the novel includes detailed descriptions of folklore, religious and cultural rituals, and family feasts in the original hometown of the Armenians that, together, construct a sense of community and togetherness, destroyed in the name of nationalism and alleged unity, and are not similarly accessible in diaspora. Mariam's narrative of the wedding of Esther, the daughter of their neighbour, is a good example of their cultural tradition and its presence in the everyday life of the community:

The wedding coincided with the feast day of St Sargis, the patron saint of youth and life. A day on which girls ate salted biscuits before bedtime to bring on a thirst in the hope future husbands would visit their dreams offering water. The feast of St Sargis marked the start of Paregentan, a period of good living and celebration, an extravagant, belly-bloating prelude to Lent and forty days of strict fasting. I loved the rituals of Paregentan, the weeks packed with feasting and merriment when presents were given and received. (25)

In addition to rituals and their meanings for the Christian community, markers that separate them from Turkish Muslims, the novel provides particular space for the meaning of food as an ethnic signifier that travels from the village feasts of Eastern Turkey to diaspora spaces in Cyprus, Britain, and the United States, all the while playing a major role in identity construction and maintenance. As food functions as a link to ethnicity and cultural tradition, Anita Mannur has suggested that food is used in cultural texts in at least two ways, to include and create a community, and to exclude and resist the dominant.

the 'culinary' most typically occupies a seemingly paradoxical space - at once a site of affirmation and resistance. Affirmation, because food often serves to mark defining moments in marking ethnicity for communities that live through and against the vagaries of diasporized realities, marred 
by racism and xenophobia. Resistance, insofar as the evocation of a culinary register can deliberately and strategically disrupt the notion that cultural identity is always readily available for consumption and commodification and always already conjoined to culinary practices. (2010: 8)

In the case of Mariam and her family, the first aspect is explicitly present from her childhood onwards, when Esther's wedding is celebrated with delicious feast dishes such as roast lamb, patila (pastry with cheese and butter), kuluk (a stew made of sheep's head), and pkhpkhig (deep fried, honey-dripping balls of dough). The importance of food is emphasized through Mariam as a part of her identity. Not only is she is referred to as "a wonderful cook who performed culinary alchemy with a shoulder of lamb and smoked paprika" (4), but her cooking and family feasts have held the family together. This is revealed in the sections following her death where the frail link with the ethnic past, Armenian cooking, is shown to have disappeared: her daughter never learnt to cook the dishes and now needs an ethnic recipe book - significantly entitled Tastes of Home (14) - to prepare an Armenian meal.

Since Makis's novel associates food with community, family, and identity, moments of homecoming and identity reconstruction in the novel often take place during meals made up of appetising dishes. For instance, when Katerina visits the diasporic Armenian family of Ara, her future lover, his mother's cooking returns her "to Gran's kitchen and happy times" (29). Not only did the "flavours and textures [...] once grace[...] our Sunday dinner table" (29), but this meal with people previously unknown to her is moment of cultural affirmation, to use Mannur's terms, as it transforms into time spent "in the midst of old friends, enjoying the playful banter, delighted to be experiencing island life from the core" (29). Similarly, the meal taken in Levon's restaurant in New York links Katerina and her mother with the latter's biological father but also offers an affirmation of her Armenian cultural identity, a moment of "belonging" to a community and also to a newly-found family:

The food arrives, dishes I recognize and have grown to love. Spicy shish and soft flatbread. Cold dishes dressed with oil and lemon. Salads laden with parsley and pomegranate. Vine leaves stuffed with rice and pine nuts. I feel a sense of belonging in Levon's decorative diner, before these plates of familiar food, a sense that Mum and I have embarked on a journey of discovery that will last a lifetime. (255)

While these moments associate ethnic identity and its reconstruction with particular traditions and the culinary, the novel indicates more generally that through them even those members of the diaspora with little knowledge of their past can be included in the diaspora community. Just as Gabi learns that her biological parents are both Armenians, Katerina's sense of identity is reconstructed and a new sense of belonging emerges. Her romantic involvement with Ara also appears to reposition her even more strongly within the diasporic Armenian community in Cyprus. The final lines of the novel are a narrative of return and 
show the remaining family in Cyprus erecting a memorial for Mariam, a new constellation that takes the form of a stone bench bearing a text plate, carved by Ara; it is a bench that will overlook Nicosia for a long time, a moment that is photographed by Gabriel who includes himself in the picture. Photographs, the novel says, "endure[...], surviv[e] oppression, tyranny, and massacre" (160), and testify to the significance of family and community that may survive through times of crisis.

Community and family, the novel suggests, are antidotes to the traumatizing processes of history. Examined in the light of Vijay Mishra's concept of diaspora trauma, the fact that the various generations of the diaspora appear to come to grips with their ghosts and traumas in various ways) - abandoning the dogma of ethnic nationalism (Gabriel), accepting past choices and mistakes (Levon), and constructing membership in a community (Gabi and Katerina) - signifies an end to all-encompassing melancholia and a new opportunity for the members of the diaspora community (see Mishra 16). While diasporas need to tell their stories, different generations may tell different stories where the hauntings of the past can figure differently.

\section{Conclusion}

This essay has argued that the representation of the Armenian genocide and its intergenerational legacy in Eve Makis's novel The Spice Box Letters (2015) is multi-layered and linked with the identity formation of the diasporic community. By using narrative conventions identified by Michael Rothberg (2000) as characteristic of traumatic realism, it provides first-hand accounts of the genocide and forced migration that still traumatize those who witness them, and shows the significance of Marianne Hirsch's (2008) postmemory in the transmission of the trauma intergenerationally through the diasporic Armenian community in Cyprus, the United Kingdom, and the United States. As a part of this, the narrative emphasizes the significance of the ethnic community and tradition through such tropes as food, which affirms the shared identity of the diaspora.

In so doing, the novel addresses ways of overcoming the traumatizing past as it brings together the dispersed family members and unites them with the larger community by using the idea of constellation both literally and figuratively in the narrative. Relying on a folktale important to those who witnessed the atrocities and were separated by them, the later generations are able to complete the constellation and understand it as an interlinked totality as well as realize the way in which it unites different temporalities. In so doing, Makis's novel is involved in imagining a new affiliation in the form of a return to a tradition and community that individuals have previously been only vaguely aware of. This appears to be one of the ways in which critics of ethnic and postcolonial writing address the concept of return as "a way for contemporary writers to understand their collective history as one in between two lands" (Oliver-Rotger 2015: 3). Seen through the prism of traumatic realism, the ending of Makis's novel, by uniting the generation that has witnessed the atrocities with their own descendants and family 
members, shows how the effects of historical and cultural traumas extend from the past to the present, while an awareness of them provides the diaspora with an opportunity to pursue life as a community.

\section{Note}

$1 \quad$ Following the established international consensus as evidenced in the Resolution of the European Parliament (2015), this paper refers to the events starting on 24 April 1915 and aiming at the extermination of Armenians in the Ottoman Empire as a genocide.

\section{References}

Çelik, Adnan, and Ergin Öpengi (2016) The Armenian genocide in the Kurdish novel: restructuring identity through collective memory. European Journal of Turkish Studies: Social Sciences on Contemporary Turkey (2016). Accessed on 15 April 2020. https://doi. org/10.4000/ejts.5291

Clifford, James (1992) Routes: Travel and Translation in the Late Twentieth Century. Cambridge: Harvard University Press.

Dean-Rucizka, Rachel (2017) Tolerance Discourse and Young Adult Holocaust Literature: Engaging Difference and Identity. New York: Routledge.

Eaglestone, Robert, and Barry Langford (2008) Introduction. In: Robert Eaglestone and Barry Langford (eds.) Teaching Holocaust Literature and Film. Houndmills: Palgrave Macmillan, 1-14.

European Parliament (2015) Resolution of 15 April 2015 on the centenary of the Armenian genocide. 2015/2590. 15 Apr. 2015. Accessed on 9 January 2020. http://www. europarl.europa.eu/doceo/document/TA-8-2015-0094_EN.html

Franklin, Ruth (2011) A Thousand Darknesses: Lies and Truth in Holocaust Fiction. Oxford: Oxford University Press.

Galip, Özlem Belçim (2016) The politics of remembering: the representation of Armenian genocide in Kurdish novels. Holocaust and Genocide Studies 30 (3): 458-487.

Hirsch, Marianne (2008) The Generation of Postmemory. Poetics Today 29 (1): 103-128.

Makis, Eve (2015) The Spice Box Letters. Dingwall: Sandstone Press.

Mannur, Anita (2010) Culinary Fictions: Food in South Asian Diasporic Culture. Philadelphia: Temple University Press.

Mishra, Vijay (2007) The Literature of the Indian Diaspora: Theorizing the Diasporic Imaginary. London: Routledge.

Oliver-Rotger, Maria Antónia (2015) Introduction: Roots and routes in American literature about return. In: Maria Antónia Oliver-Rotger (ed.) Identity, Diaspora and Return in American Literature. New York: Routledge, 1-21.

Pifer, Michael (2016) The forgetful figure: Armenian representations of trauma in Arak'el of Tabriz and Shahan Shahnur. Journal of Literature and Trauma Studies 5 (1): 65-94.

Rothberg, Michael (2000) Traumatic Realism: The Demands of Holocaust Representation. Minneapolis: University of Minnesota Press.

Scheiber, Elizabeth (2009) Car cela devient une histoire: representation of the Holocaust in the imaginative and collective memoires of Charlotte Delbo. In: Aukje Kluge and Benn E. Williams (eds.) Re-examining the Holocaust through Literature. Newcastle: Cambridge Scholars Publishing, 3-28. 
The Armenian Mirror-Spectator (2016) Eve Makis tells the story of an ordinary Armenian family. The Armenian Mirror-Spectator (online ed.), 1 September 2016. Accessed 15 April 2020. https://mirrorspectator.com/2016/09/01/eve-makis-tells-the-story-of-anordinary-armenian-family/

JopI Nyman, PhD DSocSc, is Professor of English and Vice Dean at the Philosophical Faculty, University of Eastern Finland, Joensuu Campus. He has published widely in the fields of Anglophone Literary and Cultural Studies, most recently the monographs Equine Fictions: Human-Horse Relationships in Twenty-First-Century Writing (2019) and Displacement, Memory, and Travel in Contemporary Migrant Writing (2017), and the co-edited anthologies Animals, Space and Affect (2016), Ethnic and Racial Identities in the Media (2016), and Border Images, Border Narratives (2021). His current research interests focus on transcultural literatures, border narratives, and the environmental humanities.

Address: Professor Jopi Nyman, School of Humanities, Philosophical Faculty, University of Eastern Finland, P.O. Box 111, FI-80101 Joensuu, Finland. [email: jopi.nyman@uef.fi] 
